\title{
Curriculum tinkering in situations of crises and inequalities: The case of South Africa
}

\author{
Nyna Amin ${ }^{1}$ (D) Pryah Mahabeer ${ }^{1}$ (D)
}

Accepted: 12 April 2021 / Published online: 6 September 2021

(C) UNESCO IBE 2021

\begin{abstract}
This article interrogates a curriculum recovery plan designed to obviate the loss of time due to the national response to the Covid-19 pandemic. In particular, it analyses two strategies, the first to overcome time lost and the second, to reorganize the curriculum. A description of the landscape of inequalities in South Africa serves as a conceptual and analytical framework. The article deploys the curriculum recovery plan as "data". It interrogates two strategies of the recovery plan: namely, curriculum trimming and curriculum reorganization. A major finding is that the strategies recommended in the recovery plan intensify economic stratification. Immediate, short-term, and long-term actions for reducing inequalities include excising irrelevant curricula, upskilling teachers, and reconsidering the criteria for the appointment of school leaders. Furthermore, disease-prevention strategies and social-distancing measures, which lower the teacher-student ratio, are viable solutions to reduce teacher burdens in overcrowded classrooms and to improve student learning.
\end{abstract}

Keywords Curriculum $\cdot$ Crisis $\cdot$ Inequality $\cdot$ South Africa

Covid-19 in South Africa has spared nothing in its path except, perhaps, for some wild and marine life, the geosphere, and the natural landscape. Human beings have had to endure a period of curtailed movement and interaction through enforced confinement and social distancing. The twofold loss of employment and kin, especially when the latter are the breadwinners of families, has increased the gap between the haves and the have-nots (see, for instance, Burgess and Sievertsen 2020; Ostry et al. 2020). Furthermore, based on dominant narratives shared on internet websites, social media, and reports in the news media,

Pryah Mahabeer

Mahabeerp3@ukzn.ac.za

Nyna Amin

amin@ukzn.ac.za

1 School of Education, University of KwaZulu-Natal, Durban, South Africa 
psychosocial well-being, physical health, and lifestyle are in jeopardy. Another anxiety is the ramifications from the closure of schools, which has left millions of schoolchildren without formal education (DBE 2020a).

Consequently, the 2020 academic year is shorter than previous years, which Sintema (2020) claims adversely affects learner performance. Certainly, in situations of inequality, as we describe in the next section, the consequences can be calamitous for children from impoverished backgrounds. Additionally, the loss of teaching and learning time and the questionable decisions around curriculum coverage and assessment for all subjects are other vexations. Indeed, what to teach and how much to teach form the core around which decisions relating to curriculum revolve.

Globally, the loss of teaching time is not a new phenomenon, as natural and human disasters disturb the provision of education as well as school attendance. Locally, service delivery protests and strike action continuously disrupt education when schools are burned down (Kgatle 2018) or transport to school becomes unavailable (Mokati 2017). Due to the intermittent and particularized nature of protest actions, the state has not developed policies to mitigate the loss of teaching and learning time. Covid-19, however, has stimulated the state to act: the advent of the virus led to the national lockdown proclamation, which has affected every institution of learning, their personnel, and their student bodies. The loss of school time, in this instance, is a universal experience. As such, the Department of Basic Education (DBE) released the document Draft Framework for Curriculum Recovery: Post Covid-19, which outlined the principles of managing school reopening and the attendant curriculum requirements (DBE 2020a).

In this article, we interrogate the recovery plan by reviewing two suggestions in the draft framework: that is, curriculum trimming and curriculum reorganization, and reveal the complications that surface when educators apply these aspects of the framework to a national context replete with structural inequalities and anomalies. In addition, we evaluate whether curriculum makers, as public intellectuals, have used the opportunity to reform and recraft a curriculum for greater sustainability, relevance, and care.

\section{The landscape of inequalities in South Africa}

In this section, we provide an overview of South Africa's demographics as a framework to assess the curriculum recovery plan. This situational reading of the recovery plan is necessary because education curricula represent and constitute the material basis of political motives and interests (see, Brennan 2011; Shrestha et al. 2019). It is the state's responsibility to provide the conditions for optimal learning outcomes; therefore, it is important that we describe the context of South African schooling before the coronavirus created an untenable situation. This enables us to assess the viability of the curriculum rescue plan by factoring in contextual realities, especially the matches and mismatches between curriculum policy and its possibilities. Unlike the lack of information Taba experienced over 50 years ago on the topic she described as the "science of man" (1962, p. 33), sociopolitical and economic metrics of society are widely available in the twenty-first century for critical interrogation - exemplified by reports of, amongst others, the World Bank, the International Labour Organisation, UNESCO, and the World Economic Forum. Locally, Statistics South Africa (StatsSA) provides insights that inform the analysis we offer. Next, we describe the context to which the South African curriculum recovery plan applies. 
The 2017 report of StatsSA paints a bleak picture of socioeconomic stratification in South Africa. For instance, it reveals that 55\% (30.4 million people) of the population live in poverty, while $25.2 \%$ (13.8 million of the 30.4 million people) live in absolute poverty (2017, p. 4). Figures for 2016 indicate that $13.4 \%$ are vulnerable to hunger, and that at least $61 \%$ of poor households survive on the 12 million child-support grants that the state provides (StatsSA 2017, p. 52). When comparing expenditure on food basics by poor households and by non-poor households, the gap is alarming: the former spend close to $30 \%$ of their income on food while the latter spend just $13 \%$ (StatsSA 2017, p. 100). Although the provision of essential infrastructure for the population like electricity (90.3\%), piped water (83.5\%), and flush toilets (66.6\%) has improved since 1996 (StatsSA 2017, p. 9), this infrastructure remains an incomplete project and continues to signify and contribute to inequality.

Schools, too, represent sites of inequality-ranging from under-resourced to wellresourced, categorized for funding purposes into five quintiles according to the prosperity or poverty levels of the communities in which schools are situated. Quintile 1 schools are the most destitute, as they draw their learner population from poverty-stricken households, have inadequate infrastructure, and have high student-teacher ratios. To counteract these difficulties, quintile 1 schools receive more per-capita funding from the state than quintile 5 schools. Quintile 5 schools have favourable infrastructure, receive financial support from parents to employ teachers over and above the norms set by the DBE, and are able to attract the children of middle-class households. The quintile-funding model has done little to reduce the inequalities pervasive in the education system because the country has yet to overcome such endemic problems as weak leadership, high teacher absenteeism, and inadequately skilled teachers (Spaull 2012). Unsurprisingly, impoverished quintile 1, 2 and 3 schools provide inadequate preparation of students for a poverty-free future and, more troubling, represent a bimodal school system:

South Africa is still a tale of two schools: One which is functional, wealthy, and able to educate students; with the other being poor, dysfunctional, and unable to equip students with the necessary numeracy and literacy skills they should be acquiring in primary school. (Spaull 2012, p. 14)

In an interview with a parent, a newspaper report aptly captures the reality of the bimodal system and subsequent effects on families and schooling:

Jabulani Mkhwente says that he feels so discouraged that he hasn't been able to help his children during the lockdown and fears that they will fall behind with the curriculum. "I can't read well or write well. I stopped schooling in standard 5, back in the day, because there was not enough money to take me and my siblings to school. I wish I could help them", he said. The concerned father of two says that he is not comfortable sending his children back to school. "It has been years since the government said it will address access to water and sanitation in the Eastern Cape but they haven't. They say now they are going to fix it. Until I see it for myself, my kids will stay at home until Christmas if need be", he said. (May 2020)

The parent reveals the lag that poor children have experienced during the lockdown period. Wealthy schools have continued to provide learning opportunities for students by preparing take-home learning materials for them, for home-schooling. When parents like Mkhwente are semiliterate, and more so for those who are illiterate, home-schooling is not viable.

Likewise, the lack of sanitation and water in the area where Mkhwente resides means that poor children are at higher risk when schools reopen, justifying Mkhwente's 
unwillingness to send his children to school. Undoubtedly, inequality creates anxieties about access to the basics for a dignified life, food security for survival, and education for better future prospects. In the meantime, wealthy schools have maintained communication and teaching through recourse to technology-based instruments and platforms. Schools in poor locations are unable to compete at the same level. Incontrovertibly, inequality under the conditions created by Covid-19 has increased.

We now turn to the curriculum recovery plan, which the country released in the month of May 2020, to assess whether it either explicitly or implicitly features the reduction of inequality.

\section{Policy as data: Recovering time lost in a shorter academic year}

In this section, we analyze excerpts from the curriculum recovery plan; namely, curriculum trimming and curriculum reorganization.

\section{Curriculum trimming}

We offer two excerpts here. The first refers to the percentage of the curricula that schools need to trim, while the second explains trimming.

The curriculum will have to be trimmed by $25 \%$. However, schools will complete $75 \%$ of the curriculum in the current year and $25 \%$ of the content/skills/knowledge that could not be covered and the re-organized 2021 curriculum is spread over a recovery period of two academic years i.e. 2020 and 2021 in Grades R-11. (DBE 2020a, p. 23)

Curriculum trimming involves creating space for enhancing learning, with a view to catering more effectively for [students'] needs and abilities. For purposes of our context, curriculum trimming will involve removing less important and outdated content; identifying core and extended parts of the curriculum; flexible modes of organizing study content; and using the open curriculum framework of learning targets. This is in line with the current debates in the subject of the curriculum. Literature argues that decades of overload have shaped curriculum, textbooks, tests, and teacher expectations into an industry of superficiality. For instance, many teachers know, or at least suspect, how little their learners understand and are learning, but do not know how to transform the system. Therefore, curriculum trimming will be about unburdening the curriculum, deciding what topics to keep and what to give up, to ensure that the load is manageable within the time available. (DBE 2020a, p. 15)

The juxtaposition of the two excerpts is vital for interpreting the logic of the recovery plan. It is clear that excising aspects of the curriculum is at the discretion of schools. The DBE recommends that schools do not discard content trimmed in the current year but transfer it for integration into the following year's program. This means that, in reality, 2021 will present a more challenging situation than 2020. To clarify, the 2020 year constituted a $25 \%$ reduction of content due to a $25 \%$ loss of class time-while the 2021 year will, correspondingly, constitute an expanded curriculum of $125 \%$ without a concurrent increase in class time. In practice, this means that schools will promote students to higher grades although 
they will have less content knowledge and fewer skills, and will expect them to master more content and greater skills than is usually intended for a year's study. Invariably, the 2020 crisis will extend to 2021 and beyond should the coronavirus lead to more disruption of education.

The perpetuation of poor education outcomes in South Africa is a major impediment to individual, social, and economic advancement. Consequently, the nation's interest in improving learner performance has centered on curriculum management and coverage (Schollar 2018). Since 1998, studies have revealed the reasons and complications that link teaching, learning, and poor learner performance in South Africa (Schollar 2018). These include tensions between quantity and quality of curriculum coverage (structuring and pacing); the lack of teacher pedagogy and content knowledge (Fleisch 2008); and the short time on-task, poor curriculum coverage, and the scarcity of textbooks (Hoadley et al. 2009). Low work expectations among learners and teachers, and teachers' poor conceptual knowledge of the subjects they are teaching, add other complications to the already disturbing picture of poor performance and learning outcomes (Taylor and Vinjevold 1999). The piecemeal and sluggish pace of curriculum coverage in classrooms causes many learners to lag behind each year (Taylor et al. 2003). Clearly, this complex relationship—of teachers' insufficient content knowledge, inadequate curriculum coverage, and unfavorable learner performance-persists.

The analysis of the two excerpts also reveals that the DBE is aware of the deficiencies of the present curriculum, which include irrelevant and outdated content. We argue that it makes more sense to remove outdated content completely than to teach it during the following year. Of equal concern is the awareness that teachers "do not know how to transform the system" (DBE 2020a, p. 15). If that is the case, then what will inform the decisions that schools and teachers make when trimming the curriculum? More importantly, how will schools address existing inequalities when the decision to trim the curriculum is left to teachers who may not have adequate knowledge to do so?

Evidence suggests that teacher knowledge (of pedagogy, content, and pedagogical content) is inequitably distributed in South Africa (Taylor 2019). The nation's large cohort of unqualified or underqualified teachers adversely influences the quality of curriculum coverage and the delivery of content, and poses a serious problem for managing curriculum revision (Maphalala et al. 2018). Knowledgeable teachers are more likely to make prudent decisions when trimming the curriculum than less knowledgeable ones are; similarly, less prudent curriculum decisions are more likely to affect students from impoverished backgrounds over the long term (Carr-Hill et al. 2018). In times of crisis, knowledgeable teachers might be best positioned to engage in making critical curriculum decisions since bureaucrats may lack those skills (Debarger et al. 2016).

\section{Curriculum reorganization}

Curriculum reorganisation involves reorganisation and refocusing of the curriculum to make the content more manageable. For this intervention, this will be done through the re-packaging and integrating subjects or topics, embedding particular knowledge and skills foci and balancing depth and breadth as key strategies to reduce overload. This implies that curriculum reorganisation in this context will be about merging fragmented and compartmentalised discipline-based content from related sub-topics into integrated topics of learning. This approach will facilitate hybridisation of content and knowledge in both knowledge construction and pedagogy, ena- 
bling learners to make connections among related themes and conceptual knowledge across disciplines (DBE 2020a, pp. 15-16).

The aim of curriculum reorganization is to manage content by repackaging and integrating subjects to reduce content overload. In this instance, "reducing content overload" is a theoretical idea. When curriculum developers combine content, then breadth and depth become intertwined - which, paradoxically, ends up generating complexity.

Let us explain this paradox: Integrating subjects results in content that is a dense, complex, and interconnected fusion of multiple disciplines. This complex content would require highly skilled teachers with deep insights in and aptitudes for curriculum design, selection, and hybridization. However, with expertise and resources constrained in times of crisis, teachers may not have the experience or training to have gained proficiency in content knowledge and pedagogy. Therefore, they need sufficient practice and education to meet the curriculum policy demands to improve their teaching efficiency and to be effective in teaching the curriculum in a way that would improve student learning (De Clercq et al. 2018). To disrupt the cycle of impoverished teaching and learning, teachers would have to possess advanced pedagogical and content knowledge to ensure that complex content is taught and learned effectively. It is conceivable that curriculum coverage might occur through accidental effects of other policies not linked to curriculum management (Schollar 2018), producing inconsistencies and unintentional repercussions when these policies intersect. In other words, coverage of the curriculum may not be deliberate; it could be accidental and therefore, unlikely to be replicated in future curriculum delivery, exacerbating educational inequalities.

Many young learners from impoverished backgrounds do not have access to high-quality teaching and time to construct deep understanding (Harris and Burn 2011). This deprivation makes casualties not only of the students but of the subject disciplines as well. Statistics show that approximately $80 \%$ of learners perform below the minimum expected competency level for the grade in which they are registered, resulting in their ever-increasing lack of content knowledge as they move from one grade to the next (Schollar 2018).

Seemingly, the more time teachers have to implement the curriculum, the more opportunities learners will have to practice and master new content in class. In a bimodal education system like South Africa's (Spaull 2012), children in wealthy schools will cope with complex content more easily than students from deprived contexts and poor households. In more impoverished schools, more time may be needed to teach complex content than needed in wealthier schools, contradicting the aim of the curriculum recovery plan to reduce teaching and learning time-especially in instances where teachers are incapable of teaching disconnected subjects effectively. Thus, we reveal the multiple, linked effects of impoverishment: the impoverishment of teachers and learners in impoverished settings serves to increase social and economic stratification.

\section{Contradictions and debates in the curriculum recovery plan}

This analysis, which only covered two strategies of the curriculum recovery plan, clearly shows the contradictions and paradoxes of the recommendations to mitigate the loss of a substantial part of the academic year. The intentions are subverted because they are split between simultaneously making up for the lost time and trying to cover the curriculum-creating a situation of impossibility. Trying to accomplish the former compromises 
achievement of the latter, and vice versa. Shifting the excised components to the next year expands the problem rather than solving it.

In reflecting on curriculum changes to rescue the academic year for schools, the government has a vital role in ensuring that the continuation of education programs is smooth and adequately supported. It is apparent that the unexpected appearance of Covid-19 has resulted in responses that are reactive, fragmented, and expedient due to political interests and other pressures (Carl 2002; Garrison 2009). While the state has a responsibility to make proclamations and to suggest solutions, these may not appeal to the many sectors with special interests (teachers, parents, administrators, political parties, teacher associations, and unions). Perhaps the government's response is one of panic as it has no precedents to inform decision-making in the face of the uncertainty and fatality associated with Covid-19. Nonetheless, there is also evidence of a governmental lack of vision in times of a crisis and an absence of courage to use the crisis to dismantle structural impediments built into curricula that counter successful teaching and learning.

Crises require visionary leadership to navigate complex issues and to placate the fears of the public. With Covid-19, our vision of the future is clouded by the uncertainty around the evolution of the disease. So, what shape could visionary leadership take? It would require projecting multiple scenarios and a focus on that which is attainable, like improving the conditions of quintiles 1-3 schools. It means providing water and sanitation, proper classrooms, and improved learning facilities; and upskilling teachers to undertake, for instance, curriculum trimming in a knowledgeable way. The recovery plan does not offer bold measures that inspire confidence in schools in the lower quintiles. Some of the recommendations, like adding additional hours to the school day, ignore the ability of destitute communities to arrange for travel and safety as winter draws closer and daylight hours shorten.

In explaining the recommendations, the curriculum recovery plan makes visible some of the factors that work against the efficient and effective provision of education, which would require undertaking valiant measures like reducing teacher absenteeism and removing ineffective school leaders-two important factors identified by Spaull (2012) as correlated to a bimodal education system.

Policy change or intervention, as in this instance, is a reaction to a problematic situation (Wiseman 2012). As such, decision makers must understand the subtleties of political thinking, the historical government systems, the varied constructions of power, and those in positions of authority (Ball 2007). Specifically, this translates into using power positions to improve the lives of students and the working conditions of teachers. As public intellectuals, curriculum decision-makers should be mindful of the contexts and constraints surrounding curriculum making. They should be competent enough to consistently challenge dominant hegemonic discourses and ideologies to expose relationships of power (Cooper 2005), especially the pressures to focus on excellence instead of equity (Sayed and Motala 2012).

It is rather disturbing that policymakers formulate changes in education without judicious deliberation and without considering long-term ramifications, which could result in backtracking on key curriculum developments (McDonald and Van Der Horst 2007). Certainly, the inequality in South Africa is a product of the apartheid administration's insidious policies and of the post-apartheid state's neglected redress of such policies. Instead of transformative action, policy changes become surrounded by controversy, contradictions and contestations, and socioeconomic and political difficulties (Jansen et al. 2007) within and outside the policy itself. 
Hence, there is an urgent need to go back to the ideals of the democratic turn in 1994 and to feature effective and viable educational and curriculum changes that are aligned to current societal shifts and societal needs (McDonald and Van Der Horst 2007). The poverty of 30 million South Africans demands that education policy should work in the interest of improving lives and rescuing the futures of the most vulnerable in our society.

\section{Casualties of the curriculum recovery plan}

The curriculum recovery plan is explicit about what needs to be recouped: time and curriculum coverage. It decenters the students and teachers, particularly in its rhetoric of what to do and how to do it. Policy statements are generic in nature and address broad parameters of action. In the case at hand, the curriculum recovery plan is just that: an interim set of measures to deal with the aftereffects of the closure of schools for more than two months and the resultant loss of contact time. However, the recommendations offer little, if any, direction for reducing inequalities. In fact, the revised curriculum ignores the contextual distinctions amongst schools (readiness to deliver technology-based education), glosses over pedagogical approaches (how to teach a compressed and complex curriculum), overlooks student diversity (how to accommodate differentiated needs), and is vague on the guiding principles for teachers (how to implement the recommendations).

Under normal conditions, curriculum revision starts as a careful intention, supported by broad-based consultation and the collection of evidence; and informed by value systems, promulgated, and finally implemented, in the classroom situation (Marsh 2009; Melrose 1998). It is only then that one can identify the casualties of curriculum reform: those affected by the education system's inequalities are at the top of that casualty list.

Students comprise the first group: (1) those from impoverished households whose needs and circumstances are marginally accommodated; (2) slow learners who will have to respond to complex curricula with less time to incubate ideas and concepts, and (3) upper-grade students who teachers will overload with take-home tasks but who have no support at home because their parents are semiliterate. The second group of casualties are teachers, particularly: (1) those who are underqualified and unskilled for engaging with curriculum design; (2) those working in impoverished communities; (3) those inadequately prepared for complex teaching and learning; and (4) those whose roles are largely care-driven because of the large number of school-goers in need of psycho-emotional support.

A third dimension is the silences in the curriculum itself. Some of the reasons for the extended lockdown period was to inhibit the spread of Covid-19, to increase public awareness of disease prevention, and to prepare the country for the peak expected in September 2020. It is, therefore, ironic that the recovery plan does not include content about Covid-19 in the curriculum. What is the value in recovering a curriculum but then to omit content that can prevent contracting or spreading the disease? Perhaps we need to heed Dewey's call for education to relate to students' current lives and not only to prepare them for the future (Paraskeva 2011).

It is only by examining the "how" and "why" that we can understand the dynamic forces acting on policy development and advocacy (Haddad and Demsky 1995). A crisis in education requiring urgent curriculum reform is not a new phenomenon. History shows that the disconnect between the education system and society emerges in times of social and economic disaster: war, industrialization, famine, pandemics, and genocide prompt curriculum reform. In response to education crises, William Kilpatrick averred, education should focus on "life itself and not as a mere preparation for later living" (Kilpatrick 1918, p. 320). 


\section{During times of crises, who and what drives the curriculum?}

Curriculum, as a political expression, is based on the idea that knowledge cannot be impartial. Indeed, it is subjectively propelled by interests and agendas of which implementers and consumers often are not aware. Two options are available to curriculum designers: curriculum change and curriculum continuity (Jansen 1990). It is by portraying the curriculum as an expression of the political interests, knowledge, and values of a dominant force that one has persuasive insights into curriculum predicaments and into new developments in curriculum reform (Jansen 1990).

Historically in South Africa, invisible and faceless "white male interests, white male aspirations and white male politics" controlled the educational bureaucracy and dominated the curriculum (McClintock 1993, p. 68). At that time, curriculum decision-making was imperceptible, and, once decided, imposed on South Africans. However, in recent times we can name the decisionmakers and identify the individual(s) responsible for key curriculum decisions and implementation. In terms of the National Education Policy Act no. 27 of 1996, Section 3 (4), the Minister determines the national curriculum policy framework, core syllabuses, education programs, learning standards and examination, and so on. In terms of the regulations, power is vested entirely with the minister to develop, revise, change, or dismantle such policies (DBE 2020b).

In times of crises, as exemplified by the current Covid-19 pandemic, curriculum decisions and policies have to be made swiftly and prudently, and legislated within a rapid turnaround time. Time pressures impel curriculum makers to meet progression requirements and to save the academic year. Thus, we see that urgency and speed cause an unusual circumstance, in which curriculum decisions are unfolding whilst the crisis is ongoing.

A curriculum is only as feasible as its context; hence, internal and external factors that influence the curriculum's effectiveness must be confronted concurrently with the revision process (Jansen 1990). Confronting curriculum choices is feasible when there is sufficient time; however, when time is limited, the limitations of the recovery plan pass through unchallenged.

\section{Curriculum responses to Covid-19 and beyond}

Curriculum conceived in the "new normal" has to provide students with the platform to understand unprecedented change and erratic times that allow them to connect with reality as they know it. Furthermore, it should also provide direction for curriculum policy and practice, and offer timely topics, informed by traditional school subjects, when confronted by a volatile and disturbing phenomenon like Covid- 19 .

By being more responsive to learners' needs that extend beyond the classroom, a curriculum becomes relevant to dealing with change in contemporary times (Toquero 2020). Toquero (2020) recommends that schools: use evidence-based research to inform curriculum policy, provide accessible mental health and medical support services, incorporate environmental and hygiene practices into revised curriculum policies, migrate to online learning, and upgrade teacher training for online-learning instruction. Specific to times of crises, curriculum change and development call for expert knowledge and skills - a repertoire that might be lacking among bureaucrats-which would involve substantial time and cooperation from teachers (Toquero 2020). 
On the bright side, Covid-19 has forced curriculum makers to critically reevaluate each subject in the school curriculum, though they may delay action until after the crisis subsides. Nevertheless, it is heartening to note that the DBE has identified irrelevant content and recommended the reduction of excessive assessment demands. It makes sense to maintain the aforementioned changes to the curriculum after the crisis has passed.

It is evident that schools are more likely to trim subjects in the humanities and social sciences, like history, geography, and life orientation, while leaving intact the high-status subjects like mathematics, science, and the languages. However, policymakers have overlooked content important to the lives of learners - such as life orientation and life skillsthat educators could easily integrate into other subjects. To underscore our point: privileged subjects such as mathematics and science are timetabled more frequently than those that have more direct bearing on students' lives, such as life orientation and life skills (DBE 2020c, pp. 19, 22).

It is imperative that educators outline clear and comprehensive guidelines for realizing the goals of the revised plan. Transparency and clear lines of communication are key to support the teachers, students, schools, and subject advisors (DBE 2020a).

Undoubtedly, teaching, learning, and assessment are at the center of curriculum changes during crisis times, too. Clearly, what matters is who makes these decisive curriculum decisions and to what purpose (Shay 2011). In a crisis, decisions about reforms and implementation of curricula tend to be vague and distorted, as they are outcome-based and political. We argue that, especially in times of crises, educators must make carefully considered and caring curriculum decisions. If they compromise key areas (planning, implementing, and attaining) of curriculum reform, and do not deliberate prudently on such changes, their decisions can result in compromised and misleading curricula.

Debarger et al. (2016) find decisive curriculum adaptation in crises can be an effective strategy to reform, adapt, and adopt a curriculum aligned with new visions to attain and sustain effectual teaching and learning goals. They further assume that changes in the curriculum and pedagogy are moderately "evolutionary", not "revolutionary", i.e., they are not a radical departure from existing policies (2016, p. 69) - a claim made by Tyack and Cuban (1995) as well. Evolutionary reforms require a longer period for policy change and ask us to be patient. We have to take into account that some of the inequalities endemic to education have tested the patience of those who continue to exist from day to day without a fundamental change in sight to improve their lives.

\section{Conclusion: Implications for curriculum revision}

Despite the explicit intention to deal with the loss of education of millions of children through curriculum tinkering, the recovery plan does not offer much besides a reduction in content and in the number of assessments, and shifting content into the 2021-2022 school year. Although the plan mentions such principles underpinning the curriculum as equity and inclusion, there is no "plan" for effectuating the principles- the status quo remains and, in impoverished schools and communities, deepens inequality. We can trace the omission of an action plan to the failure to link curriculum design to residents' demographic profiles. Educational attainment, after all, is strongly tied to social and cultural demography, the economy, and capital.

Covid-19 has forcefully exposed some major weaknesses of the education system in South Africa: some schools are unconducive to safe and effective teaching and learning; the absence of appropriate infrastructure, underqualified and inexperienced teachers 
complicate teaching and learning; and overcrowding is commonplace. The requirements for social distancing and prevention of disease spread may make schooling conditions better, temporarily, for teachers and students in overcrowded classrooms and schools.

Against the backdrop of poverty and massively unequal wealth distribution, it becomes clear that a one-size-fits-all recovery plan has the potential to intensify inequality. On the upside, the revision of the DBE policy forced curriculum makers to evaluate the curriculum critically. The policy's revisions - those of curriculum trimming and curriculum reorganization-give an idea of how to begin to negate inequalities. For example, the Covid-19 crisis has forced a rethinking about what teachers teach.

Immediate actions deriving from the trimming and reorganizing exercise should be the removal of outdated curricula and the insertion of relevant content, skills, and competencies. Short-term actions should focus on upskilling teachers so that they are able to make judicious curriculum decisions. Because most teachers do not have curriculum decisionmaking experience or capacity, the role of a school principal as curriculum leader becomes crucial. However, in South Africa, an incumbent with a minimum of three years of teaching experience can apply for a leadership position, which means that curriculum selection and decision making are the functions of a novice. Successful curriculum revision will also require changes in the criteria for appointing school leaders.

While the curriculum reflects the historical power-inequalities of apartheid, the longerterm possibilities will require a turn to the notion of "powerful knowledge" to reduce educational inequalities. Young $(2008$, p. 12) refers to new socioeconomic divisions between the "knowledge haves" and the "knowledge have-nots", and between "knowledge of the powerful" and "powerful knowledge". In his words, "Knowledge of the powerful is defined by who gets the knowledge in a society" (2008, p. 14), while powerful knowledge "refers not to the backgrounds of those who have most access to knowledge or who give it legitimacy" but "to what the knowledge can do or what intellectual power it gives to those who have access to it" (Young 2008, p. 14). In other words, individuals from poor socioeconomic backgrounds need not lead a life of permanent existence on the margins-curriculum revisioning that is planned around the notion of "powerful knowledge" can reduce knowledge and socioeconomic inequalities. Accessing powerful knowledge is a fundamental right for all students and not a privilege for the children of the elite; the knowledge that is not available at home is the knowledge that should be acquired at school (Young 2008). Accessing powerful knowledge is about giving all learners from poorer schools, through curriculum revision, access to trustworthy knowledge of the world and opportunities to succeed in school and thereafter.

\section{References}

Ball, S. J. (2007). Big policies/small world: An introduction to international perspectives in education policy. In B. Lingard \& J. Ozga (Eds.), The RoutledgeFalmer reader in education policy and politics. London: Routledge.

Brennan, M. (2011). National curriculum: A political-educational tangle. Australian Journal of Education, 55(3), 259-280.

Burgess, S., \& Sievertsen, H. H. (2020, April 1). Schools, skills, and learning: The impact of Covid-19 on education. VOX CEPR Policy Portal. https://voxeu.org/article/impact-covid-19-education.

Carl, A. E. (2002). Teacher empowerment through curriculum development (2nd ed.). Cape Town: Juta \& Co. 
Carr-Hill, R., Rolleston, C., Schendel, R., \& Waddington, H. (2018). The effectiveness of school-based decision making in improving educational outcomes: A systematic review. Journal of Development Effectiveness, 10(1), 61-94. https://doi.org/10.1080/19439342.2018.1440250.

Cooper, C. (2005). Accounting for the public interest: Public ineffectuals or public intellectuals? Accounting, Auditing \& Accountability Journal, 18(5), 592-608.

DBE [Department of Basic Education] (2020a). 2020: Draft framework for curriculum recovery post Covid19. Pretoria: Government Printer.

DBE (2020b). Circular no. S2 of 2020: Release of the revised annual teaching plans for Grade 7 and Grade 12 respectively. Pretoria: Government Printer.

DBE (2020c). Guidelines for development of the school timetables: Reopening of schools Covid-19. Pretoria: Government Printer.

De Clercq, F., Shalem, Y., \& Nkambule, T. (2018). Teachers' and HoDs' accountability on curriculum coverage: PILO's contribution to the theory of change in education. In P. Christie \& M. Monyokolo (Eds.), Learning about sustainable change in education in South Africa: The Jika iMfundo campaign 20152017 (pp. 147-169). Johannesburg: Saide.

Debarger, A. H., Penuel, W. R., Moorthy, S., Beauvineau, Y., Kennedy, C. A., \& Boscardin, C. K. (2016). Investigating purposeful science curriculum adaptation as a strategy to improve teaching and learning. Science Education, 101(1), 66-98.

Fleisch, B. (2008). Primary education in crisis: Why South African school children underachieve in reading and mathematics. Cape Town: Juta \& Co.

Garrison, A. H. (2009). The Influence of research on criminal justice policy-making.Professional Issues in Criminal Justice, 4(1), 9-21.

Haddad, W. D., \& Demsky, T. (Eds.) (1995). Education policy-planning process: An applied framework. Paris: UNESCO IIEP [International Institute for Educational Planning].

Harris, R., \& Burn, C. (2011). Curriculum theory, curriculum policy and the problem of ill-disciplined thinking. Journal of Education Policy, 26(2), 245-261.

Hoadley, U., Christie, P., \& Ward, C. L. (2009). Managing to learn: Instructional leadership in South African secondary schools. School Leadership and Management, 29(4), 373-389.

Jansen, J. D. (1990). Curriculum as a political phenomenon: Historical reflections on black South African education. The Journal of Negro Education, 59(2), 195-206. https://doi.org/10.2307/2295645.

Jansen, J. D., Herman, C., Matentjie, T., Morake, R., Pillay, V., Sehoole, C., \& Weber, E. (2007). Tracing and explaining change in higher education: The South African case. In Review of higher education in South Africa: Selected themes. Pretoria: Council on Higher Education.

Kgatle, M. S. (2018). The impact of the Vuwani protests on teaching and learning: Practical theological reflection. Stellenbosch Theological Journal, 4(1), 247-266. https://doi.org/10.17570/stj.2018.v4n1. a12.

Kilpatrick, W. (1918). The project method. Teachers College Record, 19, 319-335.

Maphalala, M. C., Khumalo, N. P., Buthelezi, A. B., Mabusela, M. S., Gamede, B. T., Sibaya, D. C., \& Nzima, D. R. (2018). Lessons learnt through Jika iMfundo programme in managing school curriculum in King Cetshwayo district: The programme to improve learning outcomes (PILO). In P. Christie \& M. Monyokolo (Eds.), Learning about sustainable change in education in South Africa: The Jika iMfundo campaign 2015-2017 (pp. 125-146). Johannesburg: Saide.

Marsh, C. J. (2009). Key concepts for understanding curriculum (4th ed.). London: Routledge.

May, A. (2020, April 29). Parents concerned about safety at schools after return dates were proposed. Times Live. https://www.timeslive.co.za/news/south-africa/2020-04-29-parents-concerned-about-safety-atschools-after-return-dates-set/.

McClintock, A. (1993). Family feuds: Gender, nationalism and the family. Feminist Review, 44, 61-80.

McDonald, R., \& Van Der Horst, H. (2007). Curriculum alignment, globalization, and quality assurance in South African higher education. Journal of Curriculum Studies, 39(1), 1-9.

Melrose, M. (1998). Exploring paradigms of curriculum evaluation and concepts of quality. Quality in Higher Education, 4(1), 37-43.

Mokati, N. (2017, December 29). Protests had negative effect on matric learners, says uMalusi. Independent OnLine (IOL). https://www.iol.co.za/news/south-africa/gauteng/protests-had-negative-effect-on-matric-learners-says-umalusi-12565245.

Ostry, J. D., Loungani, P., \& Furceri, D. (2020, May 18). The pandemic will leave the poor further disadvantaged. World Economic Forum in conjunction with IMF Blog. https://www.weforum.org/agenda/2020/ 05/pandemics-poor-rich-economics-coronavirus-covid19/.

Paraskeva, J. M. (2011). Conflicts in curriculum theory: Challenging hegemonic epistemologies. London: Palgrave Macmillan. 
Sayed, Y., \& Motala, S. (2012). Equity and "no fee" schools in South Africa: Challenges and prospects. Social Policy and Administration, 46(6), 672-687. https://doi.org/10.1111/j.1467-9515.2012.00862.x.

Schollar, E. (2018). Curriculum management, improving learner performance and the rise of multi-grade classes: A tangled web of challenges to the design, operation and evaluation of educational development programmes in South Africa. In P. Christie \& M. Monyokolo (Eds.), Learning about sustainable change in education in South Africa: The Jika iMfundo campaign 2015-2017 (pp. 99-123). Johannesburg: Saide.

Shay, S. (2011). Curriculum formation: A case study from history. Studies in Higher Education, 36(3), 315-329.

Shrestha, U., Williams, T. P., Samarrai, S., Geldermalsen, A., \& Zaidi, A. (2019). What is the relationship between politics, education reforms, and learning? Evidence from a new database and nine case studies. Background paper for the World Development Report.

Sintema, E. J. (2020). Effect of Covid-19 on the performance of grade 12 students: Implications for STEM education. Eurasia Journal of Mathematics, Science and Technology Education, 16(7), 1-6.

Spaull, N. (2012). Poverty and privilege: Primary school inequality in South Africa. Stellenbosch University, Department of Economics. https://www.ekon.sun.ac.za/wpapers/2012/wp132012/wp-13-2012. pdf.

StatsSA (2017). Poverty trends in South Africa: An examination of absolute poverty between 2006 and 2015. Pretoria: Statistics South Africa. https:/www.statssa.gov.za/publications/Report-03-10-06/Report-0310-062015.pdf.

Taba, H. (1962). Curriculum development: Theory and practice. San Diego, CA: Harcourt.

Taylor, N. (2019). Inequalities in teacher knowledge in South Africa. In N. Spaull \& J. Jansen (Eds.), South African schooling: The enigma of inequality Policy implications of research in education. Cham: Springer. https://doi.org/10.1007/978-3-030-18811-5_14.

Taylor, N. C., Muller, J. P., \& Vinjevold, P. (2003). Getting schools working: Research and systemic school reform in South Africa. London: Pearson Education.

Taylor, N., \& Vinjevold, P. (Eds.) (1999). Getting learning right: Report of the President's education initiative research project. Johannesburg: Joint Education Trust.

Toquero, C. M. (2020). Challenges and opportunities for higher education amid the Covid-19 pandemic: The Philippine context. Pedagogical Research, 5(4), 1-5.

Tyack, D., \& Cuban, L. (1995). Tinkering toward utopia: A century of public school reform. Cambridge, MA: Harvard University Press.

Wiseman, D. L. (2012). The intersection of policy, reform and teacher education. Journal of Teacher Education, 63(2), 87-91. https://doi.org/10.1177/0022487111429128.

Young, M. (2008). From constructivism to realism in the sociology of the curriculum. Review of Research in Education, 32(1), 1-28. https://doi.org/10.3102/0091732X07308969.

Publisher's Note Springer Nature remains neutral with regard to jurisdictional claims in published maps and institutional affiliations.

Nyna Amin is associate professor and distinguished teacher at University of KwaZulu-Natal (UKZN). Nyna teaches Discourses and Research Methodologies in Education to master's students and coordinates support for doctoral candidates. At present, she is the academic leader of research and chair of the Higher Degrees Committee in the School of Education. She has published papers in the fields of higher education, medical education, teacher education, and gender, and has co-edited a special issue on teaching and learning in higher education each year from 2012 to 2019. She is a co-founder and sub-editor of the accredited journal African Perspectives of Research in Teaching and Learning.

Pryah Mahabeer is an academic at UKZN. Pryah teaches at the Undergraduate and Postgraduate levels in Education. She supervises postgraduate students and assists in the support program to doctoral students. Her research interests lie in intellectualization of the curriculum, curriculum policy change and development, assessment, teacher education and development, gender, higher education, and social and educational research. 